\title{
Antinociceptive Effect of Lupeol: Evidence for a Role of Cytokines Inhibition
}

\author{
Flávia Oliveira deLima, ${ }^{1,2}$ Vivian Alves, ${ }^{1}$ José Maria Barbosa Filho, ${ }^{3}$ \\ Jackson Roberto Guedes da Silva Almeida, ${ }^{3}$ Luis Cezar Rodrigues, ${ }^{3}$ \\ Milena Botelho Pereira Soares ${ }^{1,4}$ and Cristiane Flora Villarreal ${ }^{1,5 *}$ \\ ${ }^{1}$ Centro de Pesquisas Gonçalo Moniz, Fundação Oswaldo Cruz, Salvador, Bahia, Brazil \\ ${ }^{2}$ Universidade Estadual de Feira de Santana, Feira de Santana, Bahia, Brazil \\ ${ }^{3}$ Universidade Federal da Paraíba, Laboratório de Tecnologia Farmacêutica, João Pessoa, Paraíba, Brazil \\ ${ }^{4}$ Centro de Biotecnologia e Terapia Celular, Hospital São Rafael, Salvador, Bahia, Brazil \\ ${ }^{5}$ Faculdade de Farmácia, Universidade Federal da Bahia, Salvador, Bahia, Brazil
}

\begin{abstract}
The present study investigates the antinociceptive properties of lupeol in models of inflammatory and post-operative pain, as well as its mechanisms of action. The effects of lupeol were tested against acetic acid-induced writhing, formalin test, carrageenan-induced hyperalgesia, and post-operative pain model. Cytokine levels were determined by ELISA. Mice motor performance was evaluated in the rota rod and open-field tests. Pre-treatment of mice with lupeol $(5-100 \mathrm{mg} / \mathrm{kg}$ IP) produced a dose-related inhibition of writhing in mice. The maximal antinociception produced by lupeol $(60 \mathrm{mg} / \mathrm{kg})$ was unaffected in mice pre-treated with yohimbine ( $\alpha 2$ adrenoceptor antagonist; $2 \mathrm{mg} / \mathrm{kg}$ IP), L-arginine (substrate for nitric oxide synthase; $600 \mathrm{mg} / \mathrm{kg}$ IP), glibenclamide (the $\mathrm{K}_{\mathrm{ATP}}$-channel blocker; $2 \mathrm{mg} / \mathrm{kg} \mathrm{IP}$ ), and methysergide maleate (serotoninergic receptors antagonist; $5 \mathrm{mg} / \mathrm{kg}$ IP). Furthermore, lupeol $(25-100 \mathrm{mg} / \mathrm{kg})$ inhibited the late phase of formalin test. Pre-treatment with lupeol $(50$ and $100 \mathrm{mg} / \mathrm{kg})$

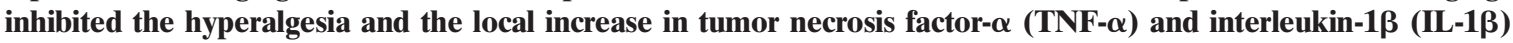
levels induced by carrageenan. In contrast, lupeol did not inhibit the post-operative pain. Lupeol-treated mice did not show any motor performance alterations or apparent systemic toxicity. Our results demonstrate that lupeol has consistent antinociceptive properties during inflammatory pain, but not post-operative pain, acting through

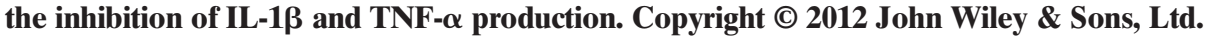

Keywords: Lonchocarpus araripensis; lupeol; antinociception; inflammatory pain; post-operative pain; cytokines.

\section{INTRODUCTION}

Triterpenes are natural components of human diets. Currently, there is a growing interest in triterpenes due to their wide spectrum of biological activities. Lupeol is a triterpene widely found in several plant genera (Siddique and Saleem, 2011). This compound has been found to exhibit a wide range of bioactivities, such as antiinflammatory (Geetha and Varalakshmi, 2001; Lucetti et al., 2010; Vasconcelos et al., 2008), anti-arthritic (Geetha and Varalakshmi, 1999), antitumoral (Hata et al., 2010), and antinociceptive (Lucetti et al., 2010; Pereira et al., 2010). The apparently low toxicity and prominent pharmacological properties in a variety of disorders indicate the possible use of lupeol as a prototype compound for development of new drugs.

Pain is one of the classic signs of the inflammatory process. Inflammatory pain is induced by different chemical mediators released during this process, which leads to phenomenon of nociceptive sensitization such as hyperalgesia (an increased response to a stimulus that is normally painful) and allodynia (pain due to

\footnotetext{
* Correspondence to: Cristiane Flora Villarreal, Laboratório de Engenharia Tecidual e Imunofarmacologia, Centro de Pesquisa Gonçalo Moniz, Fundação Oswaldo Cruz, Rua Waldemar Falcão 121, CEP 40296-710 Salvador, BA, Brazil.

E-mail: cfv@ufba.br
}

a stimulus that does not normally provoke pain) (Julius and Basbaum, 2001). Non-steroidal antiinflammatory drugs (NSAID) are among the most widely used medications due to their efficacy for a wide range of pain and inflammatory conditions. However, the longterm administration of NSAID may induce gastrointestinal ulcers, bleeding, renal disorders, and adverse cardiovascular effects, due to their inhibition of cyclooxygenases enzymes (Dogné et al., 2005; Tapiero et al., 2002). Due to the deleterious side effects attributed to the prolonged use of NSAID and their ineffectiveness in some cases, the control of inflammatory pain is still a major challenge. Considering the antiinflammatory activity of lupeol, the present study was undertaken to evaluate the antinociceptive properties of lupeol and possible mechanisms involved with its pharmacological action. In addition, we evaluated the systemic toxicity associated with the daily administration of lupeol.

\section{MATERIALS AND METHODS}

Plant material. The stem bark of Lonchocarpus araripensis Benth. (Fabaceae) was collected in September 2005 in the surroundings of Caraúbas, Rio Grande do Norte - Brazil, in authorized areas by IBAMA (Brazilian Institute for the Environment and Natural Resources) and received botanic identification by Dr. Maria de 
Fátima Agra. A voucher specimen (Agra 5559) was authenticated and deposited at the Herbarium Prof. Lauro Pires Xavier (JPB), Federal University of Paraíba, Brazil.

Extraction and isolation. The dried and powdered stem barks $(10 \mathrm{~kg}$ ) of L. araripensis were extracted with $95 \%$ $\mathrm{EtOH}$, yielding after removal of the solvent, $413 \mathrm{~g}$ of the crude ethanol extract (CEE). The CEE was suspended in $\mathrm{H}_{2} \mathrm{O}$ and partitioned with hexane and $\mathrm{CHCl}_{3}$. The hexane extract $(55.6 \mathrm{~g})$ was dissolved in hot $\mathrm{MeOH}$ $(300 \mathrm{ml})$ and left in a freezer for $24 \mathrm{~h}$, yielding a precipitate, which after recrystallization from hexane-methanol furnished pure lupeol $(1.5 \mathrm{~g})$. The mother liquor was evaporated under vacuum, and the residue was submitted to CC (silica gel column chromatography). Elution with hexane, $\mathrm{CHCl}_{3}$, and $\mathrm{MeOH}$ in an increasing polarity gradient was done to give 152 fractions. The fractions were monitored by analytical thin layer chromatography (TLC) and classified into 23 groups. The group represented by fractions 12-24 was further purified by preparative TLC over silica gel using $\mathrm{CHCl}_{3}: \mathrm{MeOH}$ (9:1) to afford more pure lupeol $(500 \mathrm{mg})$. The \% purity of lupeol used in the biological experiments as determined by highperformance liquid chromatography was 97\%. Lupeol was identified based on nuclear magnetic resonance spectroscopic data and comparison with values reported in the literature (Almeida et al., 2003).

Animals. Experiments were performed on male Swiss Webster mice from the Animal Facilities of Centro de Pesquisas Gonçalo Moniz. Animals (25-30 g) were housed at $24 \pm 1^{\circ} \mathrm{C}$, under a $12: 12 \mathrm{~h}$ light-dark cycle (lights on at 07:00 AM), with free access to chow and tap water until the day of the experiment, when only water was made available to them. Animal care and handling procedures were in accordance with the International Association for the Study of Pain guidelines for the use of animals in pain research and Institutional Animal Care and Use Committee FIOCRUZ (L-029/09). All efforts were made to minimize the number of animals used and any discomfort.

Writhing test. The intraperitoneal (IP) antinociceptive doses of lupeol were determined in mice using the writhing test. Acetic acid (0.8\% v/v, $10 \mathrm{ml} / \mathrm{kg})$ was injected into the peritoneal cavities of mice, which were placed in a large glass cylinder, and the intensity of nociceptive behavior was quantified by counting the total number of writhes occurring between 0 and $30 \mathrm{~min}$ after the stimulus injection (Collier et al., 1968).

Formalin test. Mice were placed in an open Plexiglas observation chamber for $30 \mathrm{~min}$ to accommodate to their surroundings. Mice were gently restrained while the dorsum of the hind paw was subcutaneously administered with $20 \mu \mathrm{l}$ of formalin $2.5 \%$ (1:100 dilution of stock formalin solution, $37 \%$ formaldehyde in $0.9 \%$ saline). Following injection, the mice was returned to the observation chamber. Mice were observed from 0 to $10 \mathrm{~min}$ (early phase) and from 10 to $30 \mathrm{~min}$ (late phase). The nociception score was determined by counting the time that the animal spent licking the injected limb during the observation time (Dubuisson and Dennis, 1977).
Post-operative pain model. Mice were anesthetized with $2 \%$ halothane delivered via a nose cone. After antiseptic preparation, a 5-mm longitudinal incision was made through the skin and fascia of the plantar foot. After surgery, anesthesia was discontinued, and the animals were allowed to recover in their cages. Mechanical nociceptive threshold was measured before incision (baseline), $2 \mathrm{~h}, 4 \mathrm{~h}$ and $6 \mathrm{~h}$ after incision, as the force (in grams) for paw withdrawal in response to application of von Frey filaments (Stoelting, Chicago, USA). The measurement was carried out using the up-and-down paradigm as described previously by Chaplan et al. (1994).

Carrageenan-induced hyperalgesia. Mice were slightly anesthetized with halothane and received carrageenan (100 $\mu \mathrm{g}$ per paw; $20 \mu \mathrm{l})$ subcutaneously in the plantar region of the right hind paw. Mechanical hyperalgesia was measured before and after the carrageenan injection by von Frey filaments, described above.

Motor function assays. To evaluate the possible nonspecific muscle-relaxant, locomotors, or sedative effects of lupeol, mice were submitted to the rota rod (Insight, Ribeirão Preto, Brazil) and open-field tests. Mice were treated with diazepam $(10 \mathrm{mg} / \mathrm{kg}$ IP), lupeol $(100 \mathrm{mg} / \mathrm{kg}$ IP) or vehicle, and $30 \mathrm{~min}$ after, were placed on a rotating rod at a constant speed of 5 revolutions per minute or on open-field apparatus. To rota rod, the latency to falling was measured up to $120 \mathrm{~s}$, and to open field, the number of squares crossed was registered during a period of $3 \mathrm{~min}$.

Cytokine measurement. Skin tissues were removed from the paws $2 \mathrm{~h}$ after carrageenan, in mice terminally anesthetized from each experimental group. Tissue proteins were extracted from $100 \mathrm{mg}$ tissue $/ \mathrm{ml}$ PBS to which $0.4 \mathrm{M} \mathrm{NaCl}, 0.05 \%$ Tween 20 , and protease inhibitors (0.1 mM PMSF, $0.1 \mathrm{mM}$ benzethonium chloride, $10 \mathrm{mM}$ EDTA, and $20 \mathrm{KI}$ aprotinin A/100 ml) were added. The samples were centrifuged for $10 \mathrm{~min}$ at $3000 \mathrm{~g}$, and the supernatant was frozen at $-70^{\circ} \mathrm{C}$ for later quantification. Interleukin-1 $\beta$ (IL-1 $\beta$ ) and tumor necrosis factor- $\alpha(\mathrm{TNF}-\alpha)$ levels were estimated using commercially available immunoassay ELISA kits (R\&D System, Minneapolis, MN), according to the manufacturer's instructions. The results are expressed as picograms of cytokine per milliliter of protein solution.

Evaluation of systemic effects of lupeol. Blood biochemical parameters were evaluated after treatment with lupeol. Animals were injected daily with a single dose of lupeol $(100 \mathrm{mg} / \mathrm{kg} \mathrm{IP})$ or the vehicle for seven consecutive days. At the end of treatment, blood samples were collected, and biochemical analyses were performed in serum samples. Standardized diagnostic kits by using a LABTEST $^{\circledR}$ spectrophotometer were used for determinations of the alanine amino transferase/AST, aspartate amino transferase/ALT, urea, and creatinine concentrations. In addition, histopathological analysis of the stomach was performed. After removal, each stomach was washed, fixed in $10 \%$ formalin solution, rinsed, dehydrated, and embedded in paraffin. Tissue blocks were sectioned at $3 \mu \mathrm{m}$ thickness (Cryostat CM 1800; Leica, Nussloch, Germany), stained with hematoxylineosin and observed by light microscopy $(40 \times)$ to examine morphological alterations, inflammatory cell infiltration, edema, epithelial cell loss, and necrosis, using the 
following scores: 0 , absence; 1 , discrete; 2 , moderate; 3 , moderate to intense; 4, intense (Laine and Weinstein, 1988). For each stomach, 10 fields $(40 \times)$ were analyzed per section.

Test compounds and stimuli. The test compounds used in this study were: yohimbine, L-arginine, glibenclamide, methysergide maleate, indomethacin, and dexamethasone from Sigma (St. Louis, MO). Diazepam was obtained from Cristália (Itapira, São Paulo, Brazil) and carrageenan from FMC Corporation (Philadelphia, PA). Indomethacin was dissolved in Tris- $\mathrm{HCl} 0.1 \mathrm{M} \mathrm{pH}$ 8.0 plus saline. Dexamethasone $(1 \mathrm{mg} / \mathrm{ml})$ was dissolved in ethanol (10\% in normal saline). Lupeol was dissolved in $10 \%$ DMSO plus saline, and the remaining drugs were dissolved directly in saline. Drugs were administrated by IP route.

Statistical analysis. Data are presented as means \pm standard error of the mean (SEM) of measurements made on six to seven animals in each group. Comparisons between three or more treatments were made using one-way ANOVA with Tukey's post-hoc test or, repeated measures of two-way ANOVA with Bonferroni's post-hoc test, as appropriate. All data were analyzed using Prism 5 Computer Software (GraphPad, San Diego, CA). Statistical differences were considered to be significant at $p<0.05$.

\section{RESULTS}

The antinociceptive activity of lupeol was initially evaluated using the writhing test. IP administration of lupeol $(25-100 \mathrm{mg} / \mathrm{kg}), 30 \mathrm{~min}$ before the acid injection, produced a significant $(\mathrm{P}<0.05$ and $\mathrm{P}<0.001)$ and dose-related inhibition of acetic acid-induced abdominal constrictions in mice (Fig. 1). Indomethacin (10 mg/kg IP), a standard NSAID used as positive control, also produced a significant $(\mathrm{P}<0.001)$ inhibition of acetic acid-induced writhing

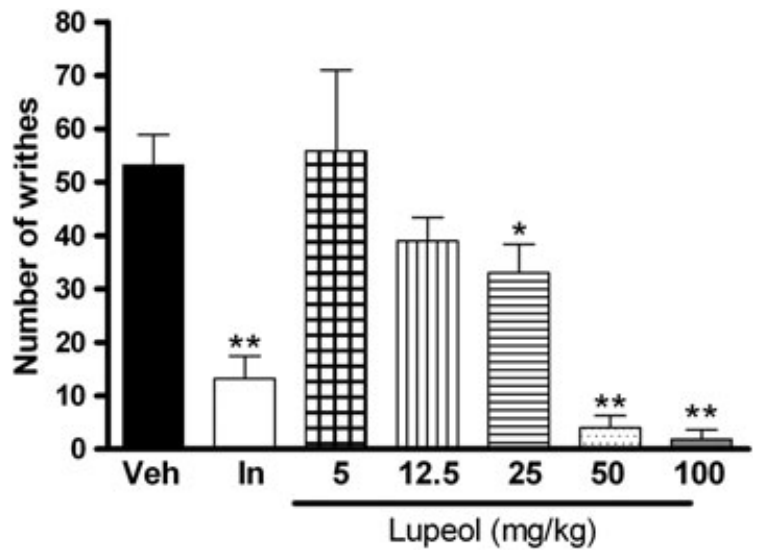

Figure 1. Effects of intraperitoneal administration of lupeol on acetic acid-induced writhing in mice. Mice were treated with lupeo $(5-100 \mathrm{mg} / \mathrm{kg})$ or vehicle (Veh; DMSO $10 \%$ in saline; control group) by intraperitoneal route $30 \mathrm{~min}$ before acetic acid $0.8 \%$ (injected at time zero). Indomethacin (In; $5 \mathrm{mg} / \mathrm{kg}$ IP) was the reference drug. Data are expressed as means \pm S.E.M.; $n=6$ mice per group. * Significantly different from control group $(P<0.05)$, ** significantly different from control group $(P<0.001)$, as determined by ANOVA followed by Tukey's test. response. Next, the role of $\mathrm{K}_{\mathrm{ATP}}$-channel, nitric oxide, adrenergic, and serotoninergic systems in the lupeolinduced antinociception was evaluated. The maximal antinociception produced by lupeol $(50 \mathrm{mg} / \mathrm{kg})$ was unaffected in mice pre-treated with glibenclamide (the

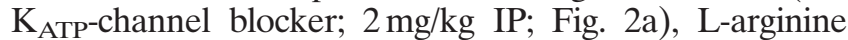
(substrate for nitric oxide synthase; $600 \mathrm{mg} / \mathrm{kg} \mathrm{IP;} \mathrm{Fig.} \mathrm{2b),}$ yohimbine $\left(\alpha_{2}\right.$ adrenoceptor antagonist; $2 \mathrm{mg} / \mathrm{kg}$ IP; Fig. 2c), and methysergide maleate (serotoninergic receptors antagonist; $5 \mathrm{mg} / \mathrm{kg}$ IP; Fig. 2d).

The antinociceptive property of lupeol was confirmed in the formalin test. Injection of formalin in control animals induced a biphasic flinching response, with the early phase ranging from 0 to $10 \mathrm{~min}$ (Fig. $3 \mathrm{a}$ ) and the late phase from 10 to $60 \mathrm{~min}$ (Fig. 3b) after the injection. Treatment with lupeol (50 and $100 \mathrm{mg} / \mathrm{kg}$ IP) $30 \mathrm{~min}$ before the formalin caused antinociceptive effect $(\mathrm{P}<0.001)$ in the late phase, but not early phase, of the formalin test. Indomethacin $(10 \mathrm{mg} / \mathrm{kg}$ IP) caused antinociceptive effects in both the early and late phases of the formalin test $(\mathrm{P}<0.001)$. Moreover, IP administration of lupeol (50 and $100 \mathrm{mg} / \mathrm{kg}$ ), $30 \mathrm{~min}$ before carrageenan, significantly reduced the mechanical hyperalgesia (Fig. 4a) $1 \mathrm{~h}$ $(\mathrm{P}<0.001)$ and $3 \mathrm{~h}(\mathrm{P}<0.001)$, but not $5 \mathrm{~h}$, after stimuli. The results obtained with control groups support the antinociceptive effects of lupeol, since the vehicle (DMSO $10 \%$ in saline) had no activity, whereas the standard drug dexamethasone $(2 \mathrm{mg} / \mathrm{kg})$ inhibited the carrageenan-induced mechanical hyperalgesia $(\mathrm{P}<0.001)$. In addition, lupeol $(100 \mathrm{mg} / \mathrm{kg})$ or dexamethasone $(2 \mathrm{mg} /$ $\mathrm{kg}$ ) inhibited the local increase of IL-1 $\beta$ (Fig 4b) and TNF- $\alpha$ (Fig $4 c)$ production induced by carrageenan. In a different way, lupeol treatment $(100 \mathrm{mg} / \mathrm{kg})$ did not attenuate incisional hyperalgesia in the post-operative pain model (data not shown in figure).

In the rota rod test, lupeol-treated mice did not show any significant performance alterations with the dose of $50 \mathrm{mg} /$ $\mathrm{kg} \quad(114.6 \pm 3.3 \mathrm{~s})$ and $100 \mathrm{mg} / \mathrm{kg} \quad(105 \pm 9.6 \mathrm{~s})$ when compared to control mice $(110.8 \pm 6.1 \mathrm{~s})$ (data not shown in figure). Similarly, IP administration of lupeol (50 and $100 \mathrm{mg} / \mathrm{kg}$ ) did not reduce the number of crossings on the open-field test (data not shown in figure). As expected, the central nervous system depressant diazepam $(10 \mathrm{mg} / \mathrm{kg}$ IP) reduced the time of mice on the rota rod and the number of crossings on the open field after $30 \mathrm{~min}$ of treatment with this standard drug. The treatment with lupeol (50 and $100 \mathrm{mg} / \mathrm{kg}$ IP) in a single dose scheme over seven consecutive days did not affect the animal corporal mass and did not induce any variation in the general appearance or toxic signs in the animals when compared to vehicle-treated mice. Values obtained for creatinine and urea levels, used as parameter of renal function, did not differ from those of control mice (Table 1). Moreover, the liver function, evaluated via hepatic enzymes (AST and ALT), was not altered by lupeol treatment in comparison to controls. Similarly, the stomach microscopical evaluation showed an intact mucosa with no inflammatory cell infiltrate, edema, erosion, or necrosis in mice daily treated with lupeol (Table 2).

\section{DISCUSSION}

The antinociceptive properties of lupeol were initially evaluated using the writhing test, a screening tool for 

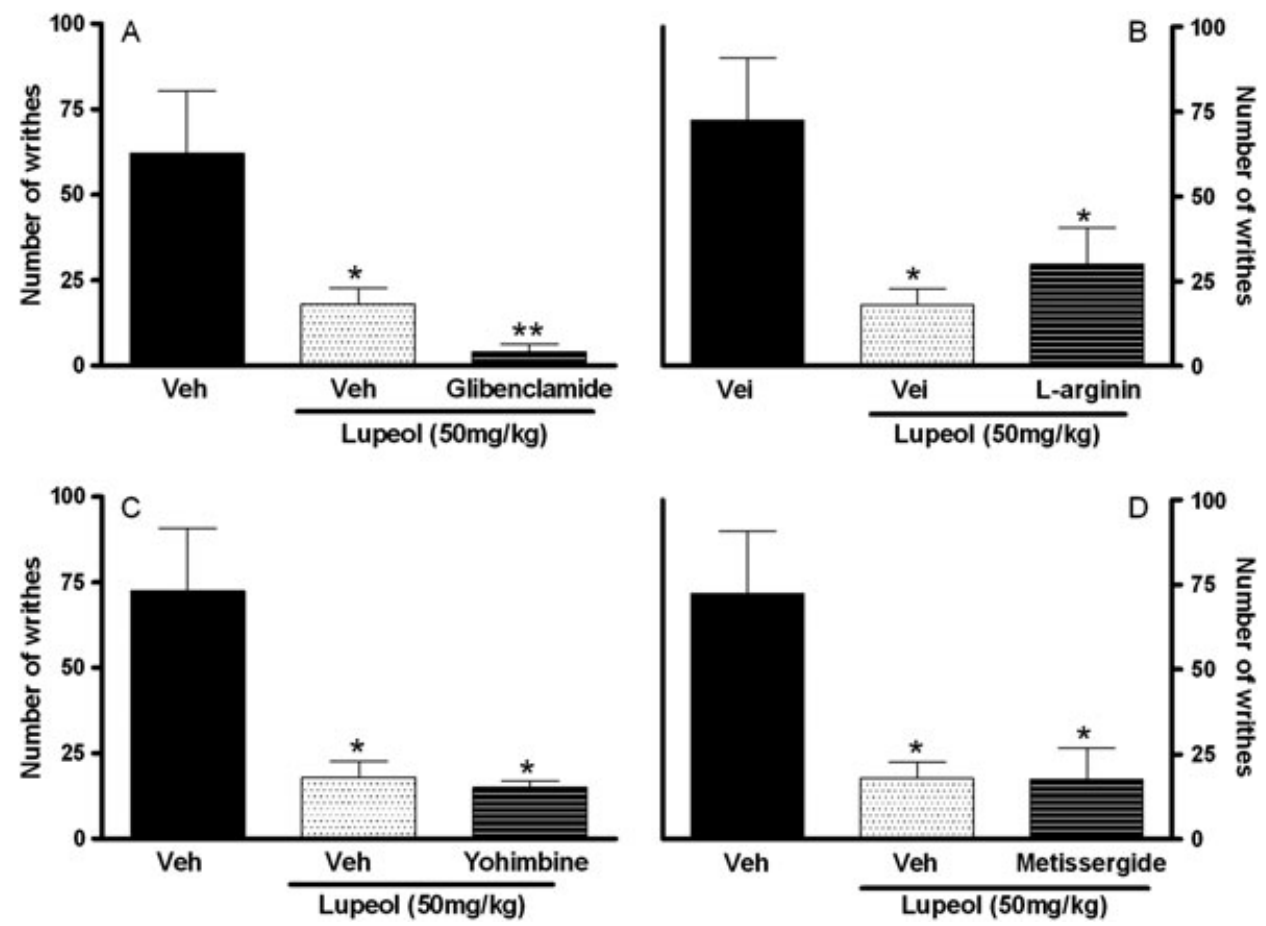

Figure 2. Assessment of possible mechanisms involved in the antinociceptive effect of lupeol on acetic acid-induced writhing in mice. Panel A: involvement of ATP-activated potassium channels: mice were treated with glibenclamide $(2 \mathrm{mg} / \mathrm{kg})$ before lupeol. Panel B: involvement of nitric oxide: mice were treated with L-arginine $\left(600 \mathrm{mg} / \mathrm{kg}\right.$ ) before lupeol. Panel C: role of $\alpha_{2}$-adrenoceptors: mice were treated with yohimbine $(2 \mathrm{mg} / \mathrm{kg})$ before lupeol. Panel D: involvement of serotoninergic receptors: mice were treated with methysergide maleate $(2 \mathrm{mg} / \mathrm{kg}) \mathrm{be}-$ fore lupeol. All antagonists were administrated by intraperitoneal route $30 \mathrm{~min}$ before lupeol $(50 \mathrm{mg} / \mathrm{kg})$. Acetic acid $0.8 \%$ was injected $30 \mathrm{~min}$ after lupeol. Control group was treated with vehicle (Veh; DMSO 10\% in saline) instead of lupeol. Data are expressed as means \pm S.E.M.; $n=6$ mice per group. * Significantly different from control group $(\mathrm{P}<0.01)$, as determined by ANOVA followed by Tukey's test.
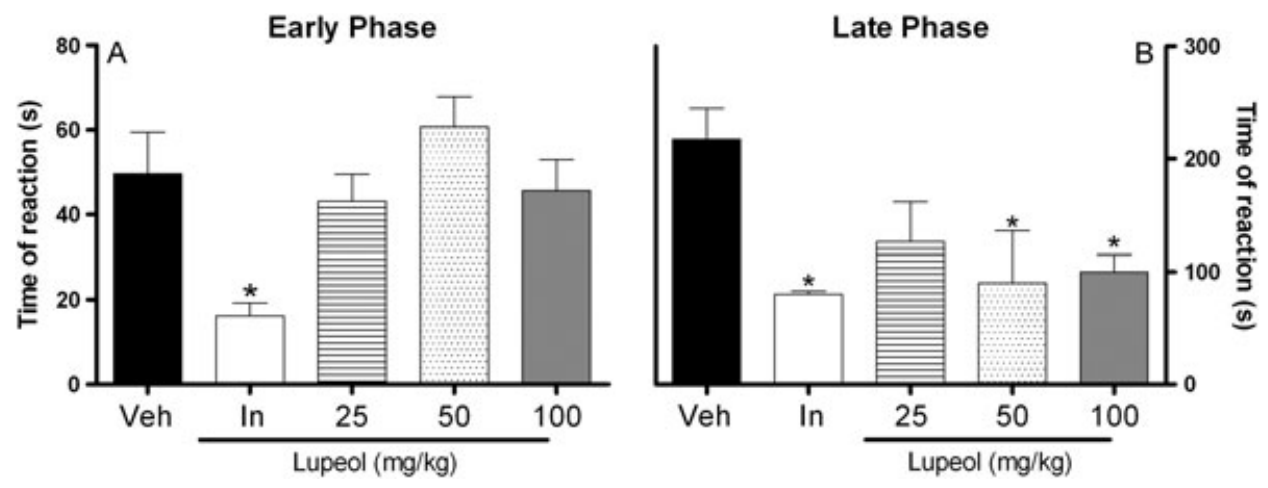

Figure 3. Effects of the lupeol treatment on the formalin-induced nociception. Panels (A) and (B) represent effects of lupeol on the early and late phases of formalin-induced nociception in mice, respectively. Mice were treated with lupeol $(25-100 \mathrm{mg} / \mathrm{kg})$ or vehicle $(V e h$; DMSO $10 \%$ in saline; control group) by intraperitoneal route $30 \mathrm{~min}$ before formalin (injected at time zero). Indomethacin (In; $5 \mathrm{mg} / \mathrm{kg}$ ) was the reference drug. Data are expressed as means \pm S.E.M.; $n=6$ mice per group. ${ }^{*}$ Significantly different from control group $(P<0.01)$ as determined by ANOVA followed by Tukey's test.

the assessment of analgesic or antiinflammatory properties of new substances (Collier et al., 1968). Lupeol produced a significant and dose-related inhibition of acetic acid-induced abdominal constrictions in mice. In contrast with the present results, Geetha and Varalakshmi (2001) showed that lupeol lacked antinociceptive effect on writhing test. These authors evaluated the lupeol effects in female rats, while in the present study, it was evaluated in male mice. Pereira et al. (2010) demonstrated the antinociceptive properties of lupeol after oral administration in male mice, suggesting that the negative results described by Geetha and Varalakshmi (2001) cannot be associated with the route of administration, but possibly with sex or animal species differences. Nociceptive studies are typically performed in male rodents because cyclic changes in the levels of sex hormones can alter the pain perception in female. In agreement with this, it has been suggested a direct role of gonadal hormones in the modulation of pain perception (Sarajari and Oblinger, 2010). Therefore, sex differences may be a reasonable explanation to the negative results described by Geetha and Varalakshmi (2001).

$\mathrm{K}_{\text {ATP }}^{+}$channel openers induce cell hyperpolarization, decrease the intracellular $\mathrm{Ca}^{2+}$ level and neurotransmitter release that may account for antinociception (Ocana et al., 2004). Similarly, it has been suggested that nitric oxide/ cGMP activation plays a role in nociceptive modulation (Duarte et al., 1990). To verify such a possibility, we examined the effect of glibenclamide, a blocker of $\mathrm{K}_{\text {ATP }}^{+}$ channel, and L-arginine, the substrate for nitric oxide synthase, on lupeol-induced antinociception. The present 

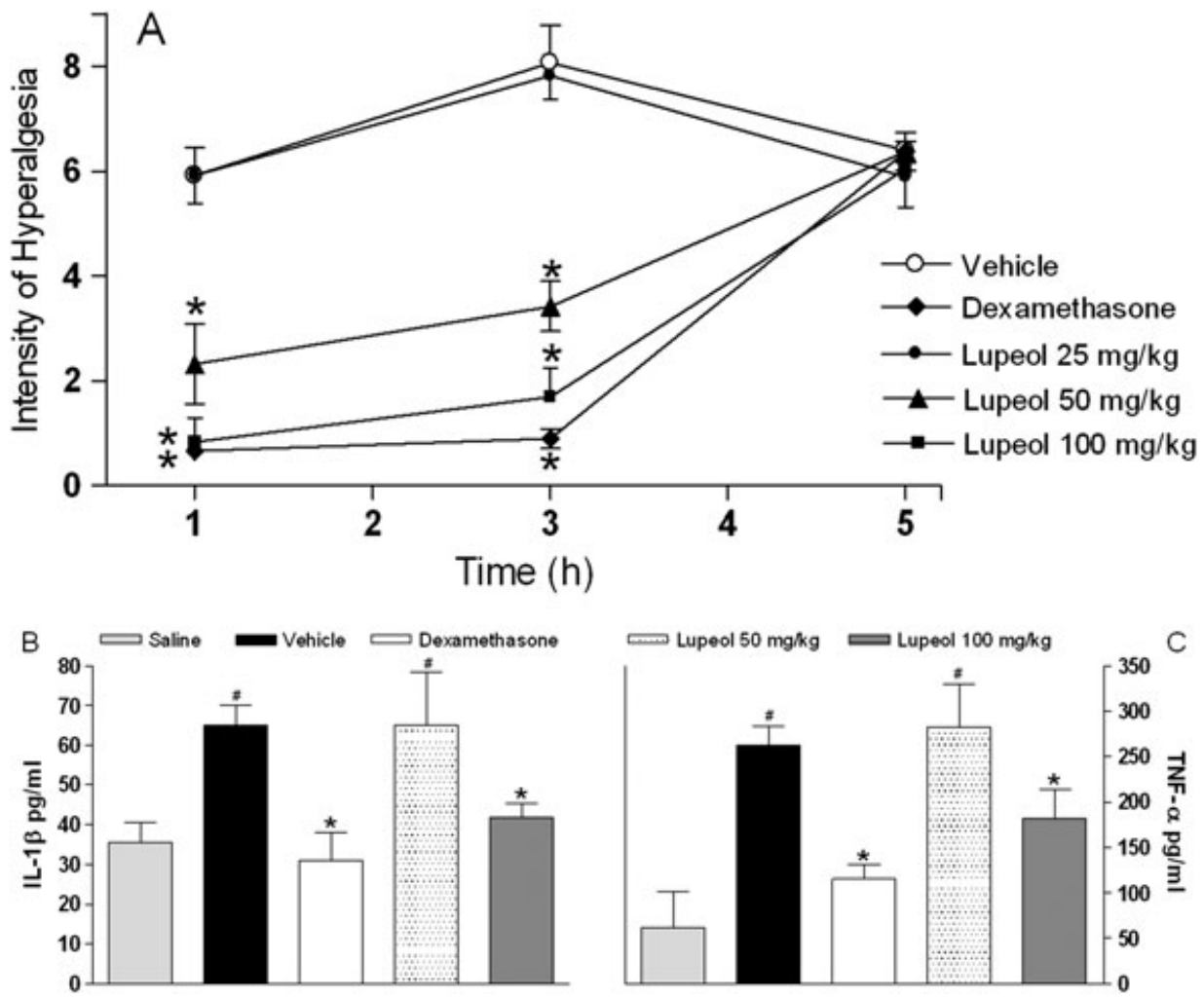

Figure 4. Effects of the lupeol treatment on inflammatory pain and cytokines levels. Panel A: mechanical hyperalgesia measured at 1, 3, and $5 \mathrm{~h}$ after the carrageenan intraplantar stimulus. Panels B and C: paw levels of IL-1 $\beta$ and TNF- $\alpha$, respectively, measured by ELISA $3 \mathrm{~h}$ after the carrageenan injection. Mice were injected with lupeol $(25-100 \mathrm{mg} / \mathrm{kg}$ ), vehicle (DMSO $10 \%$ in saline) or dexamethasone $(2 \mathrm{mg} / \mathrm{kg} ;$ reference drug) by intraperitoneal route $30 \mathrm{~min}$ before the intraplantar injection of carrageenan (injected at time zero). Saline group received intraplantar injection of saline $(10 \mu \mathrm{l} / \mathrm{paw})$ instead of carrageenan. Data are expressed as means \pm S.E.M.; $n=6$ mice per group. * Significantly different from vehicle-treated group $(\mathrm{P}<0.05)$; ${ }^{\#}$ significantly different from saline group $(\mathrm{P}<0.05)$. Panel $\mathrm{A}$ : two-way ANOVA followed by Bonferroni's test. Panels B and C: one-way ANOVA followed by Tukey's test.

Table 1. Systemic effects of daily treatment with lupeol.

\begin{tabular}{|c|c|c|c|c|}
\hline & Creatinin & Urea & AST & ALT \\
\hline Treatment & $(\mathrm{mg} / \mathrm{dl})$ & $(\mathrm{mg} / \mathrm{dl})$ & $(\mathrm{U} / \mathrm{I})$ & $(U / I)$ \\
\hline Vehicle & $0.05 \pm 0.03$ & $45.5 \pm 4.2$ & $100.6 \pm 29.3$ & $77.0 \pm 26.0$ \\
\hline Lupeol & $0.06 \pm 0.02$ & $35.7 \pm 4.8$ & $89.2 \pm 18.1$ & $58.8 \pm 8.2$ \\
\hline
\end{tabular}

Mice were daily injected with a single dose of lupeol $(100 \mathrm{mg} / \mathrm{kg})$ or vehicle for seven consecutive days. Values are expressed as means \pm SEM for five mice per group. ANOVA with Tukey's post hoc.

Table 2. Gastric effects of the daily treatment with lupeol.

\begin{tabular}{lcccc}
\hline Treatment & $\begin{array}{c}\text { Inflammatory } \\
\text { cells index }\end{array}$ & $\begin{array}{c}\text { Erosion } \\
\text { index }\end{array}$ & $\begin{array}{c}\text { Edema } \\
\text { index }\end{array}$ & $\begin{array}{c}\text { Necrosis } \\
\text { index }\end{array}$ \\
\hline Vehicle & $0.4 \pm 0.2$ & 0 & $0.6 \pm 0.2$ & 0 \\
Indometacin & $4.0 \pm 0.4 *$ & $3.0 \pm 0.6^{*}$ & $2.6 \pm 0.6^{*}$ & 0 \\
Lupeol & $0.4 \pm 0.2$ & 0 & $0.2 \pm 0.2$ & 0 \\
\hline
\end{tabular}

Mice were daily injected with a single dose of lupeol $(100 \mathrm{mg} / \mathrm{kg})$ or vehicle for seven consecutive days. The positive control group received a single dose of indomethacin $(10 \mathrm{mg} / \mathrm{kg})$. Values are expressed as means \pm SEM for five mice per group. Ten fields were analyzed per section.

*Different from vehicle-treated group, $\mathrm{p}<0.05$, ANOVA with Tukey's post hoc. results show that the antinociception induced by lupeol is not sensitive to glibenclamide or L-arginine, disproving the contributions of $\mathrm{K}_{\mathrm{ATP}}^{+}$channel and nitric oxide. Next, the possible involvement of $\alpha_{2}$-adrenoceptors and serotoninergic receptors in the antinociceptive effect of lupeol was evaluated. The maximal antinociception produced by lupeol was unaffected in mice pre-treated with yohimbine $\left(\alpha_{2}\right.$-adrenoceptors antagonist) or methysergide maleate (serotoninergic receptors antagonist), suggesting that adrenergic and serotoninergic systems play no significant role in its antinociceptive mechanisms. On the other hand, Lucetti et al. (2010) demonstrated that the lupeol antinociceptive effect was prevented by naloxone, a non-selective opioid receptor antagonist, suggesting that this effect is mediated by activation of opioid receptors.

The writhing test has long been used as a screening tool for the assessment of analgesic properties of new substances (Collier et al., 1968). This method presents a good sensitivity, although it has poor specificity. To avoid misinterpretation of the results, in the present study, the antinociceptive effects of lupeol were confirmed in the formalin test, a model of inflammatory pain which has two distinctive phases which may indicate different types of pain: the early phase, called neurogenic, is a result of direct stimulation of nociceptors and reflects centrally mediated pain; and the late phase, named inflammatory, is caused by local inflammation with a release of inflammatory and hyperalgesic mediators (Hunskaar and Hole, 1987). Treatment with lupeol caused antinociceptive effect in the late phase, but not 
early phase, of the formalin test. In fact, Lucetti et al. (2010) demonstrated that lupeol acetate produces antinociceptive effect in the formalin test. Moreover, relaxing or motor deficit effects were discarded, since lupeol administration at the therapeutic doses, did not affect the motor performance of the mice, as tested in the rota rod and open-field tests. These results corroborate the antinociceptive effect of lupeol suggested by the writhing test.

Considering that the lupeol-induced antinociception was observed just on the second phase of formalin, and the negative results of the present studies with antagonists, it is possible to suggest that the antinociceptive activity of lupeol is due, at least in part, to an antiinflammatory action. In line with this idea, lupeol is reported to have antiinflammatory properties (Geetha and Varalakshmi, 2001; Lucetti et al., 2010; Vasconcelos et al., 2008). In attempt to verify this hypothesis, the effects of lupeol were evaluated in a classical model of inflammatory pain: carrageenan-induced paw inflammation. Mechanical hyperalgesia and local cytokine production were evaluated after carrageenan administration. IP administration of lupeol reduced the mechanical hyperalgesia until $3 \mathrm{~h}$ after stimuli. In addition, lupeol inhibited the local increase of IL-1 $\beta$ and TNF- $\alpha$ production induced by carrageenan. Corroborating the present data, when tested in vitro, lupeol significantly reduced TNF- $\alpha$ and IL- $1 \beta$ production from lipopolysaccharide-stimulated macrophages (Fernández et al., 2001). Nowadays, it is well accepted that cytokines constitute a link between cellular injuries or immunological recognition and signs of inflammation (Dinarello, 2000). The key role of IL- $1 \beta$ and TNF- $\alpha$ on inflammatory hyperalgesia has been already demonstrated. It is known that a cascade of proinflammatory cytokines, which includes TNF- $\alpha$ and IL-1 $\beta$, precedes the release of the final hyperalgesic mediators, i.e. prostaglandins and sympathetic amines (Cunha et al., 2005). Cytokine antagonists were able to reduce inflammatory hyperalgesia in mice, indicating that cytokine activation is an important step in the development of inflammatory pain (Cunha et al., 2005). IL-1 $\beta$ and TNF- $\alpha$ stimulate COX-2 expression and production of prostaglandins, which are mediators involved with nociceptive sensitization (Schafers, 2003; Zucali et al., 1986). In fact, the local injection of IL-1 $\beta$ and $\mathrm{TNF}-\alpha$ produces hyperalgesia dependent on the release of prostanoids (Ferreira et al., 1988). In a previous work, lupeol significantly and dose-dependently suppressed the prostaglandin $\mathrm{E}_{2}$ production from A23187stimulated macrophages (Fernández et al., 2001). In the present work, pre-treatment with lupeol reduced the paw levels of IL-1 $\beta$ and TNF- $\alpha$ during inflammation. Since the inhibition of TNF- $\alpha$ and IL-1 $\beta$ release might lead to the inhibition of prostanoids production, it is possible that lupeol acts by preventing nociceptive sensitization. Since the sensitization of nociceptors is the common denominator of different types of pain, the reduction of IL- $1 \beta$ and TNF- $\alpha$ production can be responsible for the antinociceptive effect of lupeol described herein. In fact, Cunha et al. (2005) showed that TNF- $\alpha$ and IL-1 $\beta$ mediate the hyperalgesia induced by intraplantar administration of carrageenan in mice. Similarly, the role of TNF- $\alpha$ and IL-1 $\beta$ in overt pain models such as the formalin-evoked flinch behavior has been demonstrated (Granados-Soto et al., 2001).

It is important to recognize that pain caused by different tissue injuries is likely a result of distinct neurochemical and electrophysiologic mechanisms. In line with this concept, additional studies were conducted to determine the effect of lupeol in a model of post-operative pain induced by skin incision. In contrast to the antinociceptive effects observed in inflammatory pain models, lupeol treatment did not attenuate mechanical allodynia in incisional pain model. There is ample evidence that pain caused by inflammation or incision is based on different pathophysiologic mechanisms (Honore et al., 2000). This explains why many treatment strategies are efficacious only against specific types of pain. The present data reinforce the idea that lupeol is an antinociceptive agent useful mainly during inflammatory conditions.

The long-term administration of the available antiinflammatory-analgesic drugs may lead to development of multiple side effects such as threatening gastrointestinal ulcers, bleeding, renal disorders, and immunosuppression (Tapiero et al., 2002). Taking this possibility into consideration, the systemic effects of lupeol were studied. The daily treatment with lupeol did not affect the animal corporal mass and did not induce any toxic signs. In addition, renal and liver functions were not altered by lupeol treatment. Similarly, the daily treatment with lupeol was found safe from the viewpoint of gastric inflammatory events and ulcer induction at therapeutic dose levels. Accordingly, lupeol up to $2 \mathrm{~g} / \mathrm{kg}$ has been reported to exhibit no toxicity and adverse effect in animal studies (Patocka, 2003). In line with this idea, it is estimated that well over 2400 subjects have taken part in clinical studies with different types of triterpenes with dosage up to $25 \mathrm{~g}$ or more per day with no adverse effect reported (Moreau et al., 2002). The low toxicity and the encouraging systemic effects reported here reinforce the potential of lupeol for pharmacological development.

In contrast with non-steroidal antiinflammatory agents, inhibitors of cytokine production exhibit disease-modifying activities in animal models of chronic inflammation (Geiger et al., 1994). Thus, the downregulation of cytokines by non-toxic agents is a therapeutic strategy for the control of inflammatory diseases. In fact, anti-TNF- $\alpha$ therapies were shown to be effective in diseases that are associated with pain (Haraoui, 2005). The present study demonstrates that systemic administration of lupeol, at doses that did not induce any systemic toxicity or motor performance alteration, produced consistent antinociceptive effects in different models of inflammatory pain, but not in post-operative pain model. The results presented herein suggest that lupeol possesses analgesic activity associated with inhibition of IL-1 $\beta$ and TNF- $\alpha$ release, constituting an attractive possibility to pharmacological development. A more indepth evaluation of the mechanisms involved will need to be performed.

\section{Acknowledgements}

This work was supported by grants from Fundação de Amparo à Pesquisa do Estado da Bahia (FAPESB PNX0009/2009) and Rede Nordeste de Biotecnologia (RENORBIO).

\section{Conflict of Interest}

The authors state that there are no conflicts of interest related with the present manuscript. 


\section{REFERENCES}

Almeida JRGS, Barbosa-Filho JM, Cabral AGS, et al. 2003. Other chemical constituents of Diplotropis ferruginea Benth (Fabaceae). Rev Bras Farmacogn 14: 44-46.

Chaplan SR, Bach FW, Pogrel JW, Chung JM, Yaksh TL. 1994. Quantitative assessment of tactile allodynia in the rat paw. $J$ Neurosci Methods 53: 55-63.

Collier HOJ, Dinneen LC, Johnson CA, Schneider C. 1968. The abdominal constriction response and its suppression by analgesic drugs in the mouse. Br J Pharmacol Chemother 32 295-310.

Cunha TM, Verri WA Jr, Silva JS, Poole S, Cunha FO, Ferreira SH. 2005. A cascade of cytokines mediates mechanical inflammatory hypernociception in mice. Proc Natl Acad Sci USA 102 $1755-1760$

Dinarello CA. 2000. Proinflammatory cytokines. Chest 118 : 503-508.

Dogné JM, Supuran CT, Pratico D. 2005. Adverse cardiovascular effects of the coxibs. J Med Chem 48: 2251-2257.

Duarte ID, Lorenzetti BB, Ferreira SH. 1990. Peripheral analgesia and activation of the nitric oxide-cyclic GMP pathway. Eur $J$ Pharmacol 186: 289-291.

Dubuisson D, Dennis SG. 1977. The formalin test: a quantitative study of the analgesic effects of morphine, meperidine and brain-stem stimulation in rats and cats. Pain 4: 161-174.

Fernández MA, de las Heras B, García MD, Sáenz MT, Villar A 2001. New insights into the mechanism of action of the antiinflammatory triterpene lupeol. J Pharm Pharmacol 53: 1533-1539.

Ferreira SH, Lorenzetti BB, Bristow AF, Poole S. 1988. Interleukin-1 beta as a potent hyperalgesic agent antagonized by a tripeptide analogue. Nature 334: 698-700.

Geetha T, Varalakshmi P. 1999. Effect of lupeol and lupeol linoleate on lysosomal enzymes and collagen in adjuvant-induced arthritis in rats. Mol Cell Biochem 201: 83-87.

Geetha T, Varalakshmi P. 2001. Anti-inflammatory activity of lupeol and lupeol linoleate in rats. J Ethnopharmacol 76 : 77-80.

Geiger T, Rordorf C, Cosenti-Vargas A, et al. 1994. CGP 47969A: Effect on collagen induced arthritis in DBA/1 mice. J Rheumatol 21: 1992-1997.

Granados-Soto, Alonso-López R, Asomoza-Espinosa R, Rufino MO, Gomes-Lopes LD, Ferreira SH. 2001. Participation of COX, IL-1 beta and TNF alpha in formalin-induced inflammatory pain. Proc West Pharmacol Soc 44: 15-17.

Haraoui B. 2005. The anti-tumor necrosis factor agents are a major advance in the treatment of rheumatoid arthritis. J Rheumato/ Supp/ 72: 46-47.

Hata K, Ojihara K, Takahashi S, Tsuka T, Minami S, Okamoto Y. 2010. Effects of lupeol on melanoma in vitro and in vivo: fundamental and clinical trials. Anim Cell Tech: Basic Appl Aspects 16: 339-344.

Honore P, Rogers SD, Schwei MJ, et al. 2000. Murine models of inflammatory, neuropathic and cancer pain each generates a unique set of neurochemical changes in the spinal cord and sensory neurons. Neuroscience 98: 585-598.

Hunskaar S, Hole K. 1987. The formalin test in mice: dissociation between inflammatory and non-inflammatory pain. Pain $\mathbf{3 0}$ 103-114.

Julius D, Basbaum Al. 2001. Molecular mechanisms of nociception. Nature 413: 203-210.

Laine L, Weinstein WM. 1988. Histology of alcoholic hemorrhagic "gastritis": a prospective evaluation. Gastroenterology 94: 1254-1262.

Lucetti DL, Lucetti EC, Bandeira MA, et al. 2010. Anti-inflammatory effects and possible mechanism of action of lupeol acetate isolated from Himatanthus drasticus (Mart.) Plumel. J Inflamm 7: 2-11

Moreau RA, Whitaker BD, Hicks KB. 2002. Phytosterols, phytostanols, and their conjugates in foods: structural diversity, quantitative analysis, and health-promoting uses. Prog Lipid Res 41 457-500.

Ocana M, Cendán CM, Cobos EJ, Entrena JM, Baeyens JM. 2004 Potassium channels and pain: present realities and future opportunities. Eur J Pharmaco/ 500: 203-219.

Patocka J. 2003. Biologically active pentacyclic triterpenes and their current medicine signification. J Appl Biomed 1: 7-12.

Pereira SS, Lopes LS, Marques RB, et al. 2010. Antinociceptive effect of Zanthoxylum rhoifolium Lam. (Rutaceae) in models of acute pain in rodents. J Ethnopharmaco/ 129(2): 227-231.

Sarajari S, Oblinger MM. 2010. Estrogen effects on pain sensitivity and neuropeptide expression in rat sensory neurons. Exp Neurol 224: 163-169.

Schafers M. 2003. Intramuscular injection of tumor necrosis factor-alpha induces muscle hyperalgesia in rats. Pain 104: 579-588.

Siddique HR, Saleem M. 2011. Beneficial health effects of lupeol triterpene: A review of preclinical studies. Life Sci $\mathbf{8 8}$ 285-293

Tapiero H, Ba GN, Couvreur P, Tew KD. 2002. Polyunsaturated fatty acids (PUFA) and eicosanoids in human health and pathologies. Biomed Pharmacother 56: 215-222.

Vasconcelos JF, Teixeira MM, Barbosa-Filho JM, et al. 2008. The triterpenoid lupeol attenuates allergic airway inflammation in a murine model. Int Immunopharmacol 8: 1216-1221.

Zucali JR, Dinarello CA, Oblon DJ, Gross MA, Anderson L, Weiner RS. 1986. Interleukin 1 stimulates fibroblasts to produce granulocyte-macrophage colony-stimulating activity and prostaglandin E2. J Clin Invest 77: 1857-1863. 